\title{
Van Hiele Theory-Based Instruction and Grade 11 Students' Geometric Proof Competencies
}

\author{
Eric Machisi ${ }^{1 *}$ (D), Nosisi Nellie Feza ${ }^{2}$ (D)
}

${ }^{1}$ College of Science, Engineering \& Technology, University of South Africa, SOUTH AFRICA

${ }^{2}$ Walter Sisulu University, Buffalo City Campus, SOUTH AFRICA

*Corresponding Author: e.machisi@yahoo.com

Citation: Machisi, E., \& Feza, N. N. (2021). Van Hiele Theory-Based Instruction and Grade 11 Students' Geometric Proof Competencies. Contemporary Mathematics and Science Education, 2(1), ep21007. https://doi.org/10.30935/conmaths/9682

\begin{abstract}
South African matric results on the National Senior Certificate indicate low success in geometry, as do other African countries such as Nigeria. This poor performance affects potential career choices for students and limits the number of students who enter the highly-needed engineering fields on the African continent. Hence, this paper reports findings from a quasi-experiment involving 186 Grade 11 students from four conveniently selected township secondary schools in the Limpopo province of South Africa. The study tested the effect of Van Hiele theory-based instruction on the students' geometric proof competencies. Data were collected using a geometry proof test and analysed using nonparametric analysis of covariance. Results showed that there was a statistically significant difference in students' performance between the treatment and control groups $\left(T=595.9, p=.005, \eta p^{2}=.684\right)$. Analysis of nonparametric regression curves fitted for the treatment and control groups showed that the treatment group had higher post-test scores than the control group. It was therefore concluded that Van Hiele theory-based instruction is more effective in teaching non-routine geometric proofs than conventional instruction. The study recommends that geometry teachers in upper secondary school should consider implementing Van Hiele theorybased instruction to enhance students' geometric proof competence.

Keywords: Van Hiele theory, non-routine geometric proofs, proof competence, upper secondary, Euclidean geometry

Received: 10 Oct. $2020 \bullet$ Accepted: 24 Nov. 2020
\end{abstract}

\section{INTRODUCTION}

Literature indicates that secondary school students are expected to demonstrate geometric thinking at Van Hiele Levels 3 and 4, but research reveals that they are far below the expected level (Fabiyi, 2017; Luneta, 2015). Euclidean geometry in upper secondary school offers students a natural place to learn the art of proving. There are a variety of arguments to support the incorporation of geometric proof in the high school mathematics curriculum. In addition to laying the foundation for higher education studies in Mathematics, Science and Technology (Ndlovu \& Mji, 2012), proofs provide students with an opportunity to improve their problem-solving, critical thinking, deductive reasoning, analytical and visual skills (Jones, 2002). These skills are invaluable to the lives of the citizens of a country.

However, despite numerous justifications for including geometric proofs in secondary school mathematics curricula, reports from examiners across a number of countries indicate that Euclidean geometry questions that require students to construct non-routine geometric proofs are not well answered, with many candidates not even trying to answer such questions (Department of Basic Education, 2015; Mwadzaangati, 2015; West African Examination Council, 2015). The poor performance of high school students on Euclidean geometry proofs has been attributed to the teachers' lack of pedagogical knowledge for teaching this mathematical aspect. Teachers tend to use conventional teaching methods despite multiple calls to adopt studentcentred approaches (Harel \& Fuller, 2009; Mudaly, 2007; Siyepu, 2014). The situation is aggravated by the lack of empirical evidence to guide teachers on how they can improve the teaching of geometric proofs in upper secondary school.

Due to inadequate teaching of Euclidean geometry across grade levels, students are moving from one grade to the next, with huge gaps in their geometry knowledge and skills. As a result, many students go to upper secondary school underprepared. Studies that have assessed students' levels of geometric thought in upper secondary school indicate that most students are operating at a far lower level than expected (see for example, Alex \& Mammen, 2012; Atebe, 2008). Traditional methods would definitely not be able to resolve this situation. There is a desperate need for teachers to try something new. Research involving first-year university students in South Africa has shown that most students are lagging behind in their deductive skills (see, for example, Luneta, 2014). Some of these students are training to be mathematics teachers, and one wonders what kind of mathematics teachers they are going to be. 
The question that emerges from this background is: How should mathematics teachers in upper secondary school teach the aspect of geometric proof to enhance students' achievement? The present study assumed that a model of instruction based on the Van Hiele theory could help to address this issue.

\section{THEORETICAL FRAMEWORK}

This study was based on the theory developed by Pierre Marie van Hiele and Dina van Hiele-Geldof in their doctoral dissertations at the University of Utrecht in the Netherlands in 1957 (see Fuys, Geddes, \& Tischler, 1988). The Van Hieles argued that most students had difficulties with secondary school geometry because they had not had enough previous geometry learning experiences at lower levels (Cirillo, 2009). After close examination of the work of their students, the Van Hieles concluded that students' geometric thought appeared to progress through a series of five hierarchical levels (Van Hiele, 1984): visual, analytical, informal deduction, formal deduction, and rigour.

At the visual level, students can only recognize geometric figures (such as triangles, rectangles, squares and rhombi) by their physical appearance and not by their properties (Crowley, 1987). This is typical of pre-school learners up to Grade 2 (Malloy, 2002). At the analytical level, students are able to identify geometric figures by their properties, but cannot see the interrelationships between geometric figures and still cannot understand definitions (Crowley, 1987; Rahim, 2014; Shaughnessy \& Burger, 1985). This is typical of students in Grades 2 to 5 (Malloy, 2002). At the level of informal deduction, students can now classify geometric figures based on their properties. The concept of class inclusion is now understood and definitions become meaningful (Rahim, 2014). Nevertheless, formal reasoning is not yet understood (Van Hiele, 1984). This is typical of students in Grades 5 to 8 (Malloy, 2002). At the level of students can now construct proofs using the deductive approach, as they now understand the role of definitions, axioms, theorems and their converses (Crowley, 1987; Rahim, 2014; Shaughnessy \& Burger, 1985). This is typical of students in upper secondary school (Malloy, 2002). At the level of rigour, students understand the relationships between different axiomatic systems, and can compare, analyze and create proofs in non-Euclidean geometries (Crowley, 1987; Rahim, 2014; Shaughnessy \& Burger, 1985). This is typical of students at college or university.

According to the Van Hiele theory, students can only succeed in learning geometry if they pass through all the levels in their order without skipping any level. In order to be successful at level $(n)$, students must first master level $(n-1)$ (Usiskin, 1982). The Van Hieles concluded that the majority of secondary school students fail to succeed in learning and understanding geometry because teachers present geometry at a higher level than that of the learner (Van HieleGeldof, 1984; Van Hiele, 1984). This results in a disparity between what is being taught and the students' level of understanding. The Van Hieles warned against forcing students to a particular level when they are not ready, as this would result in students simply imitating the teacher's work without proper understanding (Van Hiele-Geldof, 1984). In order to teach geometry effectively, teachers should align their teaching with students' current Van Hiele levels (Fuys, Geddes, \& Tischler, 1988). In order for students to move from one level to the next higher level of geometric thinking, instruction should be structured according to five learning phases: information, guided orientation, explicitation, free orientation, and integration (Van Hiele, 1984).

As Abdullah and Zakaria (2013) summarize, the inquiry phase involves teacher-student conversation in order to establish students prior knowledge of the topic and to help them recognize the direction the lessons will take. During the guided orientation phase, students explore the topic and make discoveries through guided lesson activities. In the explicitation phase, students express and exchange emerging views based on what they have observed during the guided orientation phase. The free orientation phase allows students to solve open-ended and more complex tasks, such as multi-steps geometry tasks that can be solved in more than one way. In the integration phase, students review, synthesize and summarize what they have learnt in order to establish an overview of the new network of relations. After going through all these five phases, it is then that the student attains a new level of geometric thinking (Van Hiele, 1984).

If the Van Hiele theory is right, students who go to upper secondary school should at least have reached Van Hiele's third level (informal deduction) in order for them to be ready for the fourth level (deduction). This is the ideal situation. However, the situation in many mathematics classrooms is far from ideal. Several studies have found that the majority of the students operate far below their expected Van Hiele levels (Alex \& Mammen, 2012; Atebe, 2008). The present study posits that the very same theory that explains how students' levels of geometric thinking progress provides insight into how teachers can effectively teach geometric proofs in classrooms where students' difficulties with proof have been identified. Based on the Van Hiele theory, learners will not understand geometric proofs if they have not mastered the level of informal deduction.

The implication for teaching geometric proof is that, the mathematics teacher should first determine the current levels of geometric thinking of the students to see if the students are ready to learn proofs. If the students are not ready, then the teacher should first try to make up for the learning deficits in order to get the students to standard before introducing formal proofs. Another important contribution of the Van Hiele theory to the teaching and learning of geometric proofs is the idea that students' understanding of geometric concepts is largely influenced by how mathematics teachers teach. Therefore, the fact that most students come to secondary school not ready to learn geometric proofs should not be an excuse when those students leave secondary school unable to construct and write proofs. The Van Hiele teaching phases provide guidance on how to design and organize instruction in a way that enhances students' understanding of geometry concepts at any level, which by implication, includes geometric proofs.

\section{PURPOSE OF THE STUDY}

The purpose of this study was to design, implement and test the effectiveness of a Van Hiele theory-based model for teaching nonroutine geometric proofs in Grade 11.

\section{METHODOLOGY}

This research used a quasi-experimental design with nonequivalent groups. The non-equivalent groups quasi-experiment does 


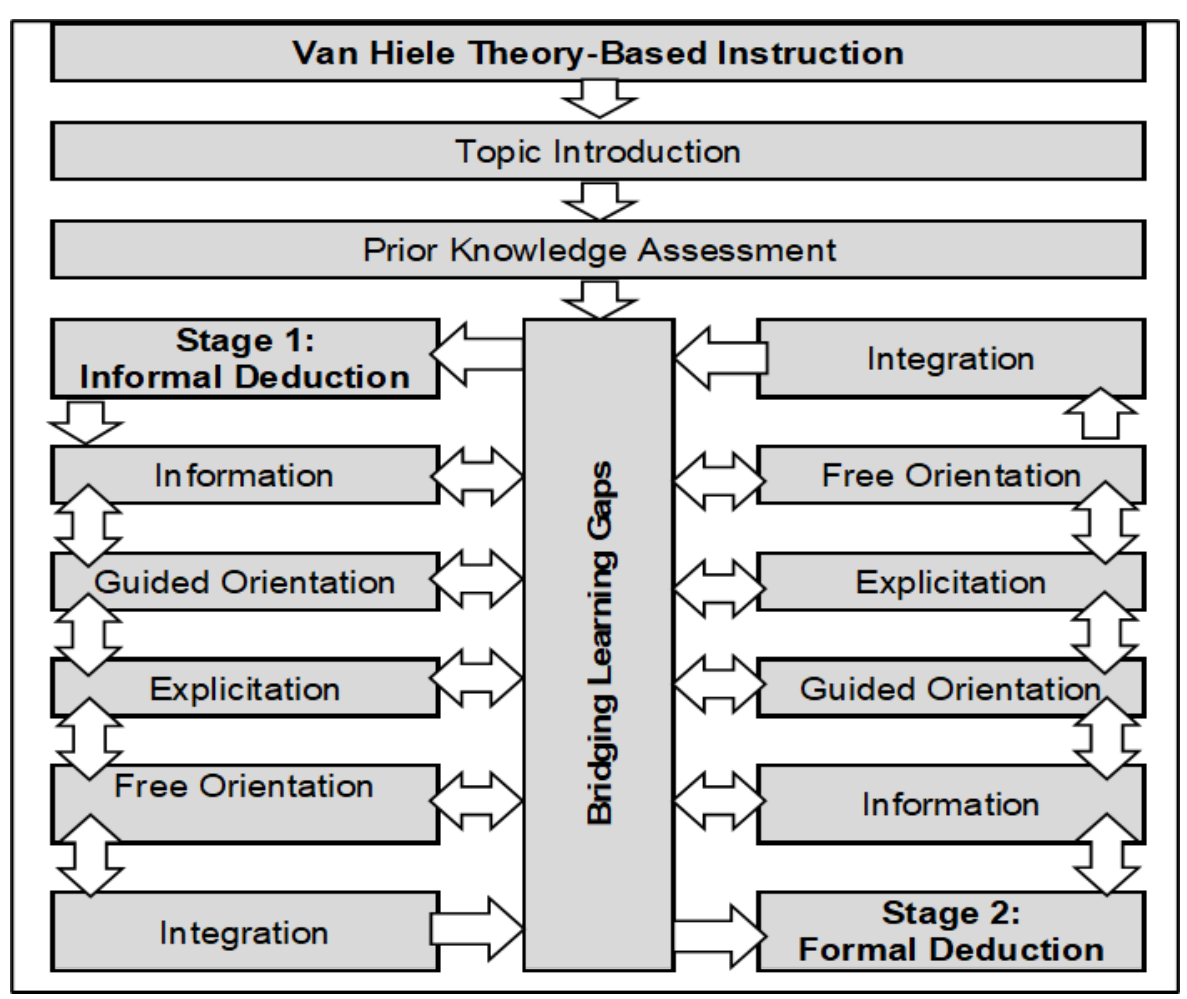

Figure 1. Proposed van Hiele theory-based model for teaching geometry proofs

not randomly assign participants to treatment and control groups. Four secondary schools from two townships in Limpopo province were conveniently chosen to take part in the study. Two secondary schools in Seshego Township formed the experimental group, while two other secondary schools in Mankweng Township formed the control group. Schools were matched on the basis of their quintile status. All four schools were categorized as quintile 3 government funded non-fee schools. These schools are located in low socio-economic status areas characterized by low family income, low education and high unemployment. For most students coming from these areas, what is happening within the four walls of the mathematics classroom is what determines student achievement.

A total of 186 Grade 11 students from four intact classes participated in the study. Of these, 82 students were in the experimental group, while 104 were in the control group. Students in the experimental group were taught by the researcher using Van Hiele theory-based instruction, while those in the control group were taught by their teachers the regular way. The model of instruction implemented in the experimental group schools is shown in Figure 1.

Topic introduction involved giving students a brief history of Euclidean geometry, discussing the role of geometry in human life, and the professions in which Euclidean geometry knowledge and skills are useful. A prior knowledge assessment test was administered to the experimental group students to assess their current levels of geometric thought. This was based on the concepts of Grade 8-10 geometry. Test item analysis was done to identify learning gaps and students who needed to be placed on a remedial programme. Bridging lessons were given to students to try to close identified learning gaps. Students at risk were put on a continuous remedial programme for the duration of the topic.

In Stage 1, students were informed of what they are going to learn about in Grade 11 Euclidean geometry. We discussed the terminology of the topic which included words such as: chord, diameter, radius, segment, arc, sector, secant, tangent, perpendicular, parallel, corresponding, alternate, vertically opposite, interior, exterior, supplementary, complementary, adjacent, co-interior, minor segment, major segment, and cyclic quadrilateral. During the guided orientation phase, students engaged in practical investigation activities using readymade sketches in the Geometer's Sketch Pad (GSP). The teacher guided students in these activities. In the explicitation phase, students exchanged views based on what they had observed in their explorations. During the free orientation, students explored properties of given geometric figures using the GSP, without interference from the teacher. In the integration phase we had a whole class discussion to summarize findings of the investigations. The teacher explained that there is no guarantee that the results obtained in the empirical investigations are always true. This is because the results were obtained through trying out a few cases, which does not necessarily mean that they are valid in all cases. The teacher used this to emphasize the need for formal proof.

Stage 2 was divided into two parts. The first part was the proving of theorems, and the second part was the proving of riders. In both cases, students were informed of what they are going to learn about. The teacher guided students through the proving process. Students were given the opportunity to share their opinions on what they had learnt from the guided orientation activities. Students then practised the proving process in pairs and in small groups without the guidance of the teacher. They reported back on their findings and we had a whole class discussion to integrate the findings.

The experiment was carried out over a period of four weeks. The researcher developed a geometry proof test consisting of four long questions. Seven mathematics experts were requested to rate the relevance of the test items using a criterion adapted from Yaghmaie (2003). Item content validity indices were calculated using a modified kappa statistic $\left(k^{*}\right)$. A mean kappa value of .99 was obtained which 


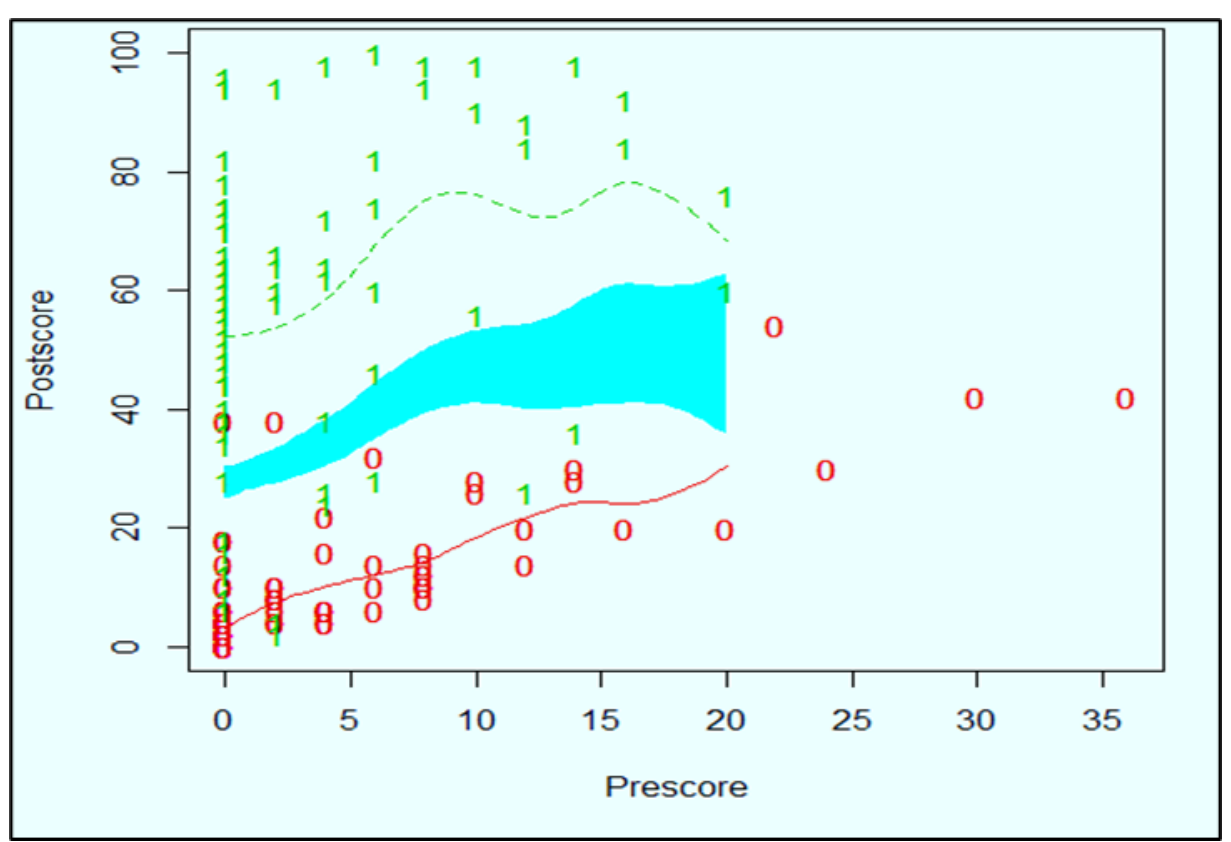

Note: 0 = Control group; $1=$ Treatment group

Figure 2. Non-parametric smoothing curves for the control and treatment groups

indicated that there was near perfect agreement among the raters that the test items were a valid measure of students' geometric proof competencies. Reliability of the test was assessed using the test retest criterion. Pearson's correlation coefficient value of .824 was obtained, which fell above the minimum reliability threshold of .70 recommended by Paiva, et al. (2014). It was concluded that the test was reliable. Both control and experimental group students were given the same test before and after intervention.

Data were analysed using non-parametric ANCOVA, with pre-test score as a covariate.

\section{FINDINGS AND DISCUSSION}

Test of equality of non-parametric regression curves fitted for the experimental and control groups using the smoothing model 'sm. ancova' function in $\mathrm{R}$ indicated a statistically significant difference in the performance of the two groups ( $h=2.26, p=.000)$, at the $5 \%$ level of significance (see Figure 2).

Further statistical analysis of post-test percentage scores using a locally weighted polynomial smoother 'loess. ancova' function in the fANCOVA package in $\mathrm{R}$, confirmed that there was indeed a statistically significant difference in students' performance between the experimental and control groups $\left(T=595.9, p=.005, \eta_{p}{ }^{2}=\right.$ .684).Visual inspection of locally estimated scatter-plot smoothing (LOESS) curves fitted for the experimental and control groups using bias-corrected Akaike Information Criterion (AICc) revealed that the experimental group had higher scores than the control group (see Figure 3).

Analysis of the descriptive statistics produced by the LOESS function in $\mathrm{R}$ showed that the median score for the experimental group was 49.288 points greater than that of the control group. Thus, the Van Hiele theory-based model of instruction had a greater positive impact on the students' geometric proof competencies than the conventional teaching approach. These findings are consistent with previous research on the effect of Van Hiele theory-based instruction on students' levels of geometric thinking.

While a number of studies have evaluated the effect of Van Hiele theory-based instruction on students' understanding of geometry concepts, none of the studies found in literature implemented Van Hiele theory-based instruction in teaching geometric proofs to students who go to upper secondary school with huge gaps in their geometry knowledge and skills. Abdullah and Zakaria (2013), Alex and Mammen (2016), and Serow (2008), implemented Van Hiele-based instruction in the teaching and learning of properties of triangles and quadrilaterals at Grades 9 and 10. Meng (2009), and Shi-Pui and Ka-Luen (2009) implemented Van Hiele phase-based instruction in the teaching and learning of solid geometry. Siew, Chong, and Abdullah (2013) applied Van Hiele phase-based instruction in teaching the concept of symmetry of two-dimensional shapes at Grade 3 level. Liu (2005) implemented Van Hiele-based instruction in teaching one of the theorems of circle geometry. These studies focused on developing the geometric thinking of students at elementary and junior levels. Much attention has been directed towards developing students' visual, analytical and informal deduction skills, and less attention has been paid to developing students' geometric proof competencies.

With numerous reports indicating that upper secondary school students are unable to achieve formal deduction due to inadequate prior knowledge, the findings of this study show that it is possible to help many students who go to upper secondary school geometry classes underprepared to catch up and master geometric proofs. Teachers should therefore not use students' Van Hiele levels at the beginning of the year to predict students' geometry performance at the end of the year. Most students are victims of bad teaching in the past. Given the right instruction, these students can still make substantial improvements within a short period of time as demonstrated by this study. This is confirmed by Gutiérrez, Jaime, and Fortuny (1991), who found that is possible for a student to master two Van Hiele levels simultaneously. 


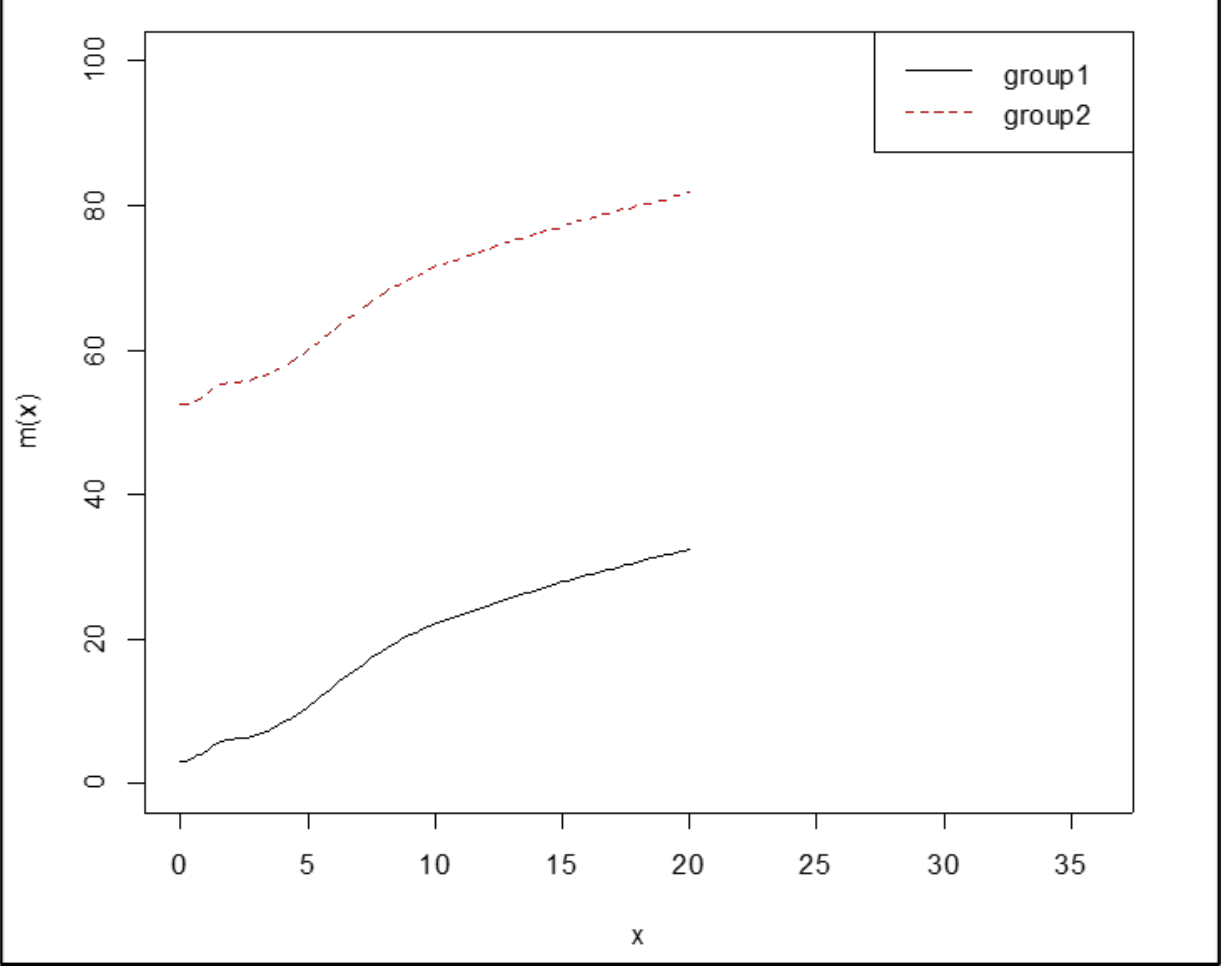

Note: Group 1 = Control group; Group 2 = Treatment group

Figure 3. Curves for treatment and control groups

\section{RECOMMENDATIONS AND CONCLUSION}

Based on the findings of this study, we recommend that mathematics teachers who still find it difficult to make geometric proofs accessible to most of their students should consider switching from regular instruction to Van Hiele theory-based instruction. Not every teacher is aware of the Van Hiele theory and its implications for geometry teaching and learning. Pre-and in-service teachers should therefore be trained on how to implement Van Hiele theory-based instruction in their geometry lessons. Future research should replicate this study with a larger sample of randomly selected schools to obtain more definitive results to give more weight to current findings. Another possible topic for future research is to explore students' reflections on the implementation of Van Hiele theory-based instruction in order to elicit the exact elements of the Van Hiele model that make it more effective than regular instruction. Based on the students' views, suggestions on ways to improve the Van Hiele model could also be uncovered.

\section{REFERENCES}

Abdullah, A. H., \& Zakaria, E. (2013, May). Enhancing Students' Level of Geometric Thinking Through Van Hiele's Phase-based Learning. Indian Journal of Science and Technology, 6(5), 4432-4446. https://doi.org/10.17485/ijst/2013/v6i5.13

Alex, J. K., \& Mammen, K. J. (2012). A Survey of South African Grade 10 Learners' Geometric Thinking Levels in Terms of the Van Hiele Theory. Anthropologist, 14(2), 123-129. https://doi.org/10.1080/ 09720073.2012.11891229
Alex, J. K., \& Mammen, K. J. (2016). Lessons Learnt from Employing van Hiele Theory Based Instruction in Senior Secondary School Geometry Classrooms. Eurasia Journal of Mathematics, Science ans Technology, 12(8), 2223-2236. https://doi.org/10.12973/eurasia. 2016.1228a

Atebe, H. U. (2008). Students' van Hiele Levels of Geometric Thought and Conception in Plane Geometry: A Collective Case Study of Nigeria and South Africa (Unpublished doctoral dissertation). Rhodes University, Grahamstown, South Africa.

Cirillo, M. (2009, November). Ten things to consider when teaching proof. Mathematics Teacher, 103(4), 251-527. https://doi.org/ 10.5951/MT.103.4.0250

Crowley, M. L. (1987). The van Hiele Model of the Development of Geometric Thought. In M. M. Lindquist, Learning and Teaching Geometry, K-12, 1987 Yearbook of the National Council of Teachers of Mathematics (pp. 1-16). Reston, VA: The National Council of Teachers of Mathematics.

Department of Basic Education. (2015). National Senior Certificate Examination 2014 Diagnostic Report. Pretoria: Department of Basic Education.

Fabiyi, T. R. (2017). Geometry Concepts in Mathematics Perceived Difficult to Learn by Senior Secondary School Students in Ekiti State, Nigeria, Journal of Research \& Method in Education, 7(1), 83-90. https://doi.org/10.9790/7388-0701018390

Fuys, D., Geddes, D., \& Tischler, R. (1988). The van Hiele Model of Thinking in Geometry among Adolescents. Journal for Research in Mathematics Education, 3, 1-196. https://doi.org/10.2307/749957 
Gutiérrez, A., Jaime, A., \& Fortuny, J. M. (1991). An alternative paradigm to evaluate the acquisition of the van Hiele levels. Journal for Research in Mathematics Education, 22(3), 237-251. https://doi.org/10.5951/jresematheduc.22.3.0237

Harel, G., \& Fuller, E. (2009). Current Contributions Toward Comprehensive Perspectives on the Learning and Teahing of Proof. In D. A. Stylianou, M. L. Blanton, \& E. J. Knuth, Teaching and Learning Proof Across the Grades: A K-12 Perspective (pp. 355-370). New York, NY: Routledge. https://doi.org/10.4324/ 9780203882009-21

Jones, K. (2002). Issues in the teaching and learning of geometry. In L. Haggarty (Ed.), Aspects of Teaching Secondary School Mathematics: Perspectives on Practice (pp. 121-139). London: Routledge Falmer. https://doi.org/10.1002/tl.62

Liu, K.-W. (2005). The Effectiveness of van Hiele-Based Instruction (Unpublished master's thesis), University of Hong Kong, Pokfulam, Hong Kong SAR.

Luneta, K. (2014, December). Foundation Phase Teachers' (Limited) Knowledge of Geometry. South African Journal of Childhood Education, 4(3), 71-86. https://doi.org/10.4102/sajce.v4i3.228

Luneta, K. (2015). Understanding students' misconceptions: An analysis of final Grade 12 examination questions in geometry. Pythagoras, 36(1), Art. \#261. https://doi.org/10.4102/ pythagoras.v36i1.261

Malloy, C. E. (2002). The van Hiele Framework. In D. K. Pugalee, J. Frykholm, H. Slovin, A. Johnson, \& C. E. Malloy, Navigating Through Geometry Grades 6-8. Reston, VA: National Council of Teachers of Mathematics.

Meng, C. C. (2009). Enhancing Students' Geometric Thinking Through Phase-Based Instruction Using Geometer's Sketchpad: A Case Study. J. Pendidik dan Pendidikan, Jil, 24, 89-107.

Mudaly, V. (2007). Proof and Proving in Secondary Schools. Pythagoras, 66, 64-75. https://doi.org/10.4102/pythagoras.v0i66.81

Mwadzaangati, L. (2015). Mathematical Knowledge for Teaching Geometric Proof: Learning from Teachers' Practices. Proceedings of the Ninth Congress of the European Society for Research in Mathematics Education (pp. 3308-3308). Prague, Czech Republic: CERME.

Ndlovu, M., \& Mji, A. (2012). Pedagogical implications of students' misconceptions about deductive geometrical proof. Acta Academia, 44(3), 175-205.
Paiva, C. E., Barroso, E. M., Carneseca, E. C., Souza, C. d., Santos, F. T., López, R. V., \& Paiva, B. S. (2014). A critical analysis of test-retest reliability in instrument validation studies of cancer patients under palliative care: a systematic review. BMC Medical Research Methodology, 14(8). https:// doi.org/10.1186/1471-2288-14-8

Rahim, M. H. (2014). Research implications for teaching and learning strategies in undergraduate mathematics. European Journal of Science and Mathematics Education, 2(2A), 122-130. https://doi.org/ 10.30935/scimath/9634

Serow, P. (2008). Investigating a phase approach to using technology as a teaching tool. Proceedings of the 31st Annual Conference of the Mathematics Education Research Group of Australasia (pp. 445-452). MERGA.

Shaughnessy, M. J., \& Burger, W. F. (1985, September). Spadework Prior to Deduction in Geometry. Mathematics Teacher, 78, 419-428. https://doi.org/10.5951/MT.78.6.0419

Shi-Pui, K., \& Ka-Luen, C. (2009). The van Hiele Phases of Learning in Studying Cube Dissection. Retrieved from http://math.unipa.it/ grim/21_project/Kwan358-363.pdf

Siew, N. M., Chong, C. L., \& Abdullah, M. R. (2013). Facilitating Students' Geometric Thinking Through van Hiele's Phase-Based Learning Using Tangram. Journal of Social Sciences, 9(3), 101-111. https://doi.org/10.3844/jssp.2013.101.111

Siyepu, S. (2014). Analysis of Van Hiele's Theory in Circle Geometry: A Focus in FET Level. In M. Lebitso, \& A. Maclean (Ed.), Proceedings of the 20th Annual National Congress of the Association for Mathematics Education of South Africa. 2, pp. 61-63. Kimberley: AMESA.

Usiskin, Z. (1982). Van Hiele Levels and Achievement in Secondary School Geometry. Chicago: University of Chicago.

Van Hiele, P. M. (1984). A Child's Thought and Geometry. In D. Fuys, D. Geddes, \& R. Tischler (Eds.), English Translation of Selected Writings of Dina van Hiele-Geldof and Pierre M. van Hiele (pp. 247256). Brooklyn, NY: Brooklyn College.

Van Hiele-Geldof, D. (1984). The Didactic of Geometry in the Lowest Class of Secondary School. In D. Fuys, D. Geddes, \& R. Tischler (Eds.), English Translation of Selected Writings of Dina van HieleGeldoff and Pierre M. van Hiele (pp. 10-222). Brooklyn, NY: Brooklyn College.

West African Examination Council. (2015). Chief Examiners Report. Lagos: WAEC.

Yaghmaie, F. (2003). Content validity and its estimation. Journal of Medical Education, 3(1), 25-28. 